CASE REPORT

\title{
Importance of Oral Hygiene Habits in Mentally Disabled Children
}

\section{${ }^{1}$ Usha Mohan Das, ${ }^{2}$ Beena JP, ${ }^{3}$ Divya Reddy}

${ }^{1}$ Principal, Professor and Head, Department of Pedodontics and Preventive Dentistry,VS Dental College and Hospital, Bengaluru Karnataka, India

${ }^{2}$ Senior Lecturer, Department of Pedodontics and Preventive Dentistry,VS Dental College and Hospital, Bengaluru, Karnataka India ${ }^{3}$ Postgraduate Student, Department of Pedodontics and Preventive Dentistry, VS Dental College and Hospital, Bengaluru Karnataka, India

Correspondence: Usha Mohan Das, Principal, Professor and Head, Department of Pedodontics and Preventive Dentistry VS Dental College and Hospital, Bengaluru, Karnataka, India, e-mail: ushymohandas@gmail.com

\begin{abstract}
Background : The main factor related to gingival/periodontal problems in disabled individuals is the inadequacy of the plaque removal from the teeth. Motor coordination problems and muscular limitation in neuromuscularly disabled individuals along with the difficulty in understanding the importance of oral hygiene in mentally disabled individuals have resulted in the progression of inflammatory diseases.

Case report : This report describes a case of cerebral palsy child who developed gingival hyperplasia due to poor oral hygiene practices which remarkably improved by proper motivation and adaptation of oral hygiene measures.

Conclusion : It is important that the caretakers especially mother is informed about the importance of maintaining proper oral hygiene and the harmful effects of not doing so. It forms our duty to guide them towards maintaining good oral hygiene and thereby help in improving overall health of these children.
\end{abstract}

Keywords : Mentally disabled, oral hygiene, gingival hyperplasia.

\section{INTRODUCTION}

Handicap is the loss or limitation of opportunities to take part in the normal life of the community on an equal level with others due to physical and social barriers. ${ }^{1}$ Cerebral palsy is one of these neuromuscularly handicaps, which has specific motor skill problems, delay in developmental milestones, as well as physical findings that might include abnormal muscle tonus, reflexes, and persistent infantile reflexes. ${ }^{2,3}$ In disabled individuals the process of developing gingival/periodontal diseases does not differ from nondisabled individuals. There are no differences in prevention of the diseases and the treatment modalities between these groups. The main factor related to gingival/periodontal problems in disabled individuals is the inadequacy of the plaque removal from the teeth. Motor coordination problems and muscular limitation in neuromuscularly disabled individuals along with the difficulty in understanding the importance of oral hygiene in mentally disabled individuals have resulted in the progression of inflammatory diseases. ${ }^{4-6}$

The following report describes a case of cerebral palsy child who developed gingival hyperplasia due to poor oral hygiene practices which remarkably improved by proper motivation and adaptation of oral hygiene measures.

\section{CASE REPORT}

A male patient aged 6 years reported to Department of Pedodontics and Preventive dentistry, VS Dental College and Hospital, Bengaluru. Patient's mother complained of severe bleeding from gums from past 1 week and inability of the child to eat. The child is known case of cerebral palsy with microcephaly and mental retardation with developmental age of only a few months (Fig. 1). Patient showed minimal response to verbal commands. 


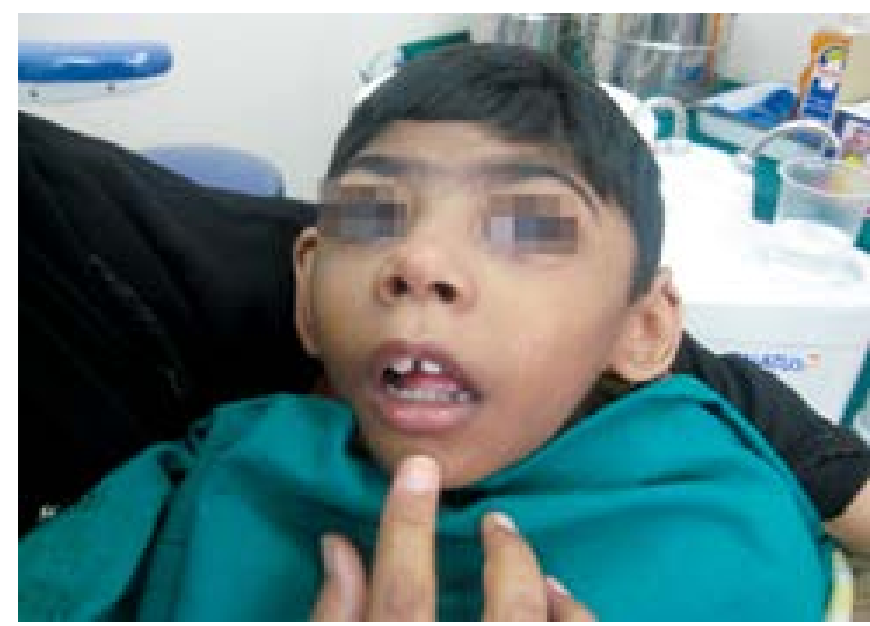

Fig. 1: Patient showing cerebral palsy with microcephaly and mental retardation

On intraoral examination, erythematous gingival overgrowth was noted on labial and palatal aspects of 54 (Fig. 2) and labial aspect of 64 . On palpation, profuse bleeding was noted.

A detailed case history was taken and it was noted that the patients teeth were cleaned once daily by mother by wiping with a wet cloth. No brushing or use of any dentifrice was done from the beginning.

Depending on clinical examination and based on the oral hygiene status of the patient, a provisional diagnosis of inflammatory gingival hyperplasia due to poor oral hygiene was obtained.

Pediatric opinion on general state of patient was obtained and after performing all the necessary blood investigations, excision of hyperplastic gingiva in relation to 54 was planned and done under local anesthesia (Fig. 3). The excisional biopsy specimen was sent for histopathological examination (Fig. 4).

Meanwhile, mother was educated regarding the importance of oral hygiene, method of brushing and other oral hygiene practices. Chlorhexidine mouth rinse was also advised and the surgical excision of the tissue in relation to 64 was deferred till the final diagnosis was obtained.

The histopathological examination confirmed the diagnosis of inflammatory gingival hyperplasia secondary to poor oral hygiene status.

Patient was recalled after 1 week for excision on the other side, i.e in relation to 64 but it was observed that there was spontaneous healing of the gingival tissues probably due to the oral hygiene measures adopted (Figs 5 and 6). Therefore

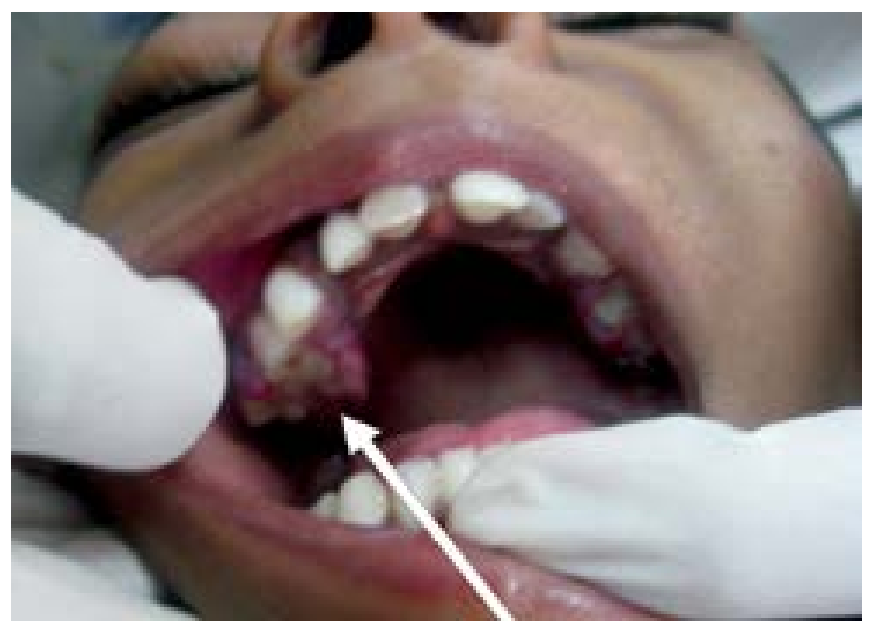

Fig. 2: Intraoral photograph showing gingival overgrowth labial and palatal to 54

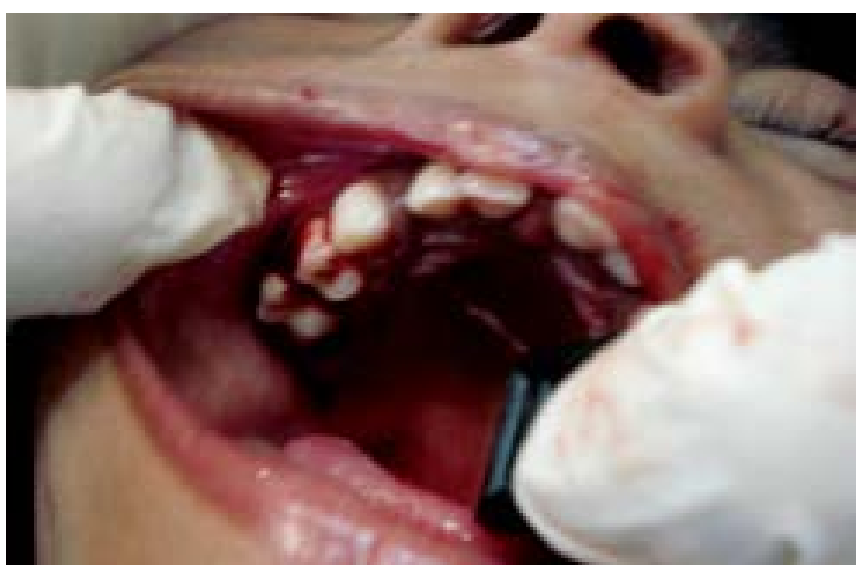

Fig. 3: Immediately after surgical excision

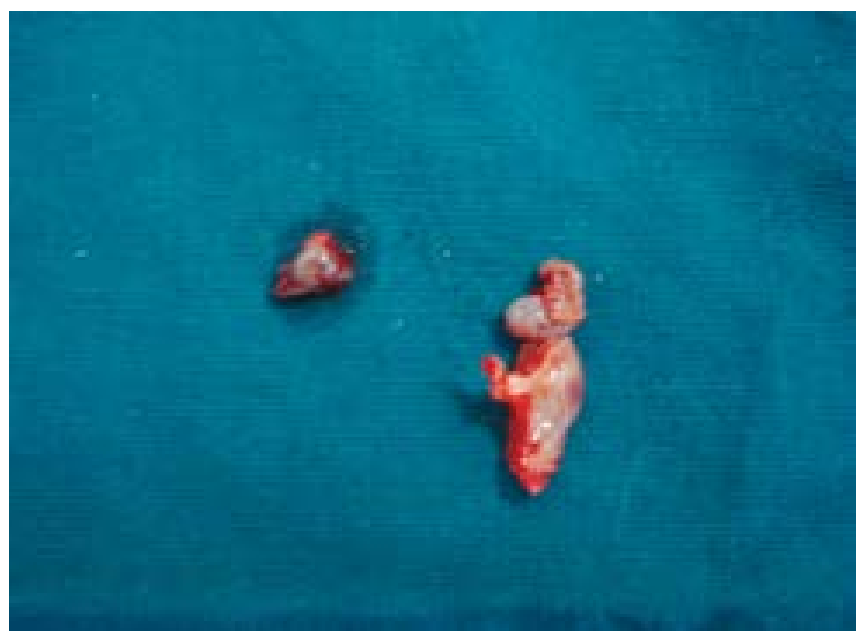

Fig. 4: Excision biopsy specimen 


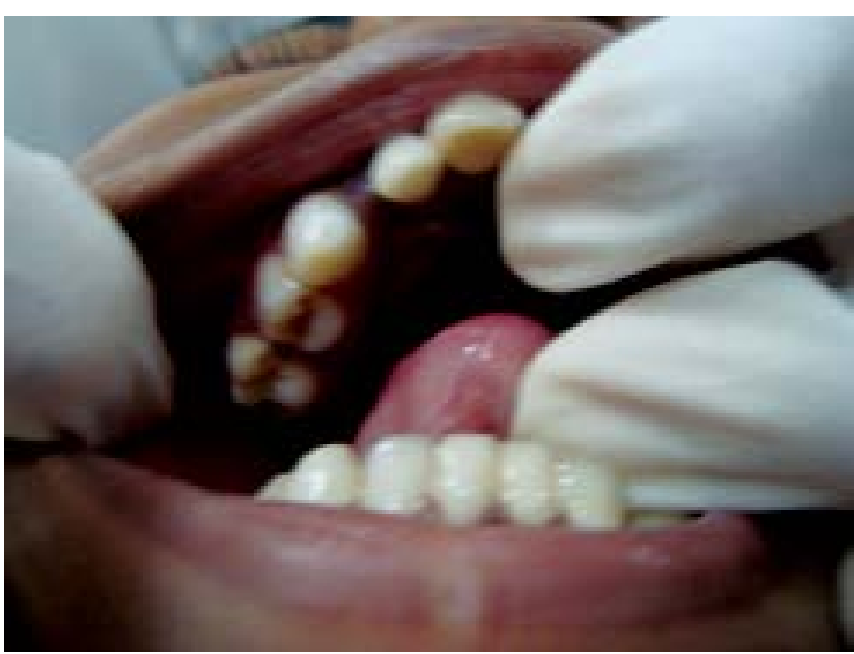

Fig. 5: One week after surgery

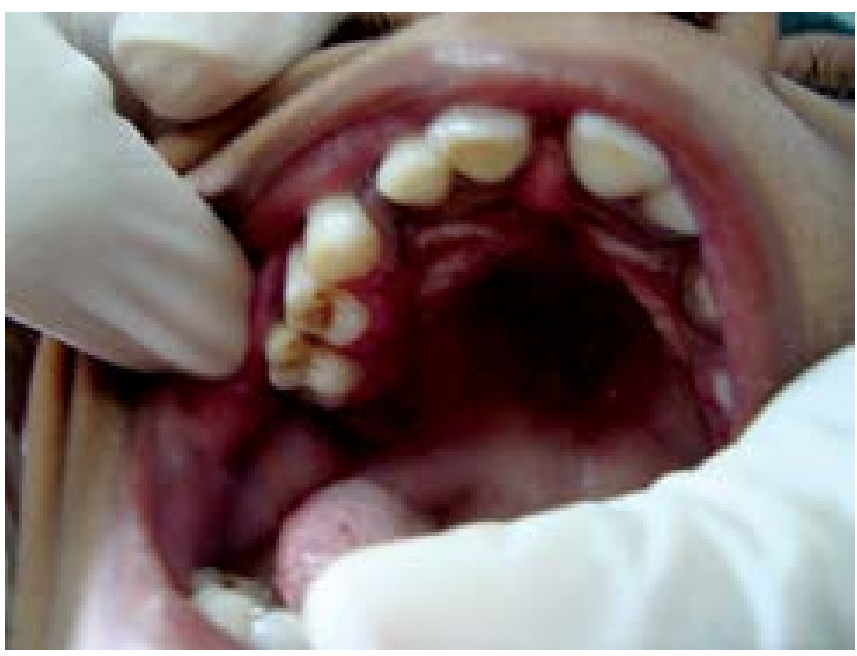

Fig. 6: Spontaneous regression on other side

parents were advised to continue with oral hygiene measures and patient is being reviewed regularly.

\section{DISCUSSION}

Oral hygiene practices are voluntary physical activities that have at least two requirements: Motivation and manual dexterity. ${ }^{7}$ Thus, poor oral hygiene is perhaps more prevalent among mentally retarded persons compared to other individuals. ${ }^{8}$ Many studies have found an inverse relationship between the levels of mental retardation and oral hygiene status; the lower the IQ score, the higher the oral hygiene index score. ${ }^{9,10}$ The provision and/or supervision of oral hygiene by parents have been reported to be lower for disabled children than for nondisabled children. ${ }^{11}$ This may lead to various complications like gingival and periodontal diseases, dental caries thereby affecting the nutritional status of the child.

The mechanical control of dental plaque in disabled individuals generally causes some difficulties, is found to be time-consuming, and sometimes ineffective $\mathrm{e}^{12,13}$ and also the lack of parental education and motivation leads to the development of gingival and periodontal diseases which thereby affects the nutrition status of these children. In this case report, the parents were from low socioeconomic background and were unaware of the importance of oral hygiene practices. No oral hygiene measures were being used or have been used which can be accounted for the gingival hyperplasia.

Various studies have shown that the effectiveness of manual and electric toothbrushes is limited by the manual dexterity and skill of the user. ${ }^{14}$ As a result, chemical plaque control has been recommended as an alternative and adjunctive to mechanical plaque control in these special patient groups. ${ }^{15}$ The effectiveness of chlorhexidine (CHX) have widely been investigated in various patient populations, including the disabled, and the results have led CHX to be defined as the "gold standard." $16-20$ The combination of mechanical and chemical plaque control seemed to be even more beneficial than only using a mouthwash. ${ }^{21,22}$

In the present case, spontaneous healing of the gingival hyperplasia was noted in just 1 week after the adoption of chemical (CHX) and mechanical plaque control measures.

Particularly the education and motivation of parents, especially mother can be considered to be the main factor for the adoption of oral hygiene measures and improved oral hygiene status of the patient.

\section{CONCLUSION}

Oral health problems in mentally disabled children may be because of the parental belief of a reduced importance of oral health in comparison to the over all scheme of health management or maybe more time is devoted to assist these children in other daily activities which are seen to be more important compared to their nondisabled counterparts. It is important that the caretakers especially mother is informed about the importance of maintaining proper oral hygiene and the harmful effects of not doing so. It forms our duty to guide them towards maintaining good oral hygiene and thereby help in improving overall health of these children. 


\section{REFERENCES}

1. Waldman HB. Almost four million children with disabilities. ASDC J Dent Child1995 May-Jun;62(3):205-209.

2. Tahmassebi JF, Curzon ME. The cause of drooling in children with cerebral palsy--hypersalivation or swallowing defect? Int J Paediatr Dent 2003 Mar;13(2):106-111.

3. Ekedahl C, Mansson I, Sandberg N. Swallowing dysfunction in the brain-damaged with drooling. Acta Otolaryngol 1974 Jul-Aug;78(1-2):141-149.

4. Tesini DA. An annotated review of the literature of dental caries and periodontal disease in mentally retarded individuals. Spec Care Dentist 1981 Mar-Apr;1(2):75-87.

5. Cutress TW. Periodontal disease and oral hygiene in trisomy 21. Arch Oral Biol 1971 Nov;16(11):1345-1355.

6. Nunn JH. The dental health of mentally and physically handicapped children: A review of the literature. Community Dent Health 1987 Jun;4(2):157-168.

7. Shapira J, Stabholz A. A comprehensive 30-month preventive dental health program in a pre-adolescent population with Down's syndrome: A longitudinal study. Spec Care Dentist 1996 Jan-Feb;16(1):33-37.

8. Tesini D. Age, degree of mental retardation, institutionalization, and socioeconomic status as determinants in the oral hygiene status of mentally retarded individuals. Community Dent Oral Epidemiol 1980 Oct;8(7):355-359.

9. Butts JE. Dental status of mentally retarded children. II. A survey of the prevalence of certain dental conditions in mentally retarded children in Georgia. J Public Health Dent 1967;27(4):195-211.

10. Powell EA. A quantitative assessment of the oral hygiene of mentally retarded residents in a state institution. J Public Health Dent 1973;33(1):27-34.

11. Allison PJ, Lawrence HP. A paired comparison of dental care in Canadians with Down syndrome and their siblings without Down syndrome. Community Dent Oral Epidemiol 2004 Apr;32(2):99106.

12. Chikte UM, Pochee E, Rudolph MJ, Reinach SG. Evaluation of stannous fluoride and chlorhexidine sprays on plaque and gingivitis in handicapped children. J Clin Periodontol 1991 May;18(5):281-286.

13. Mann J, Wolnerman JS, Lavie G, Carlin Y, Garfunkel AA. Periodontal treatment needs and oral hygiene for institutionalized individuals with handicapping conditions. Spec Care Dentist 1984 Jul-Aug;4(4):173-176.

14. Cronin MJ, Dembling W, Conforti NJ, Liebman J, Cugini M, Warren PR. A single-use and 3-month clinical investigation of the comparative efficacy of a battery-operated power toothbrush and a manual toothbrush. Am J Dent 2001 Nov; 14 Spec No:19B24B.

15. Bay LM, Russell BG. Effect of chlorhexidine on dental plaque and gingivitis in mentally retarded children. Community Dent Oral Epidemiol 1975 Nov;3(6):267-270.

16. Storhaug K. Hibitane in oral disease in handicapped patients. J Clin Periodontol 1977 Dec;4(5):102-107.

17. Francis JR, Hunter B, Addy M. A comparison of three delivery methods of chlorhexidine in handicapped children. I. Effects on plaque, gingivitis, and toothstaining. J Periodontol 1987 Jul;58(7):451-455.

18. Brayer L, Goultschin J, Mor C. The effect of chlorhexidine mouthrinses on dental plaque and gingivitis in mentally retarded individuals. Clin Prev Dent 1985 Jan-Feb;7(1):26-28.

19. Gargoine CA. Use of chlorhexidine gluconate for bacterial plaque prevention in children with cerebral palsy. Rev Assoc Paul Cir Dent 1980 May-Jun;34(3):220-225. (Port).

20. Lang NP, Brecx MC. Chlorhexidine digluconate: An agent for chemical control and prevention of gingival inflammation. J Periodont Res 1986 Nov;21(suppl 16):74-89.

21. Brecx M, Brownstone E, MacDonald L, Gelskey S, Cheang M. Efficacy of Listerine, Meridol and chlorhexidine mouthrinses as supplements to regular tooth cleaning measures. J Clin Periodontol 1992 Mar;19(3):202-207.

22. Brecx M, Macdonald LL, Legary K, Cheang M, Forgay MG. Long-term effects of Meridol and chlorhexidine mouthrinses on plaque, gingivitis, staining, and bacterial vitality. J Dent Res 1993 Aug;72(8): 1194-1197. 